\title{
Children using sound sensors to improve school environmental health
}

\author{
Alexandra Souza, Ana Rita Alves \\ Ciência Viva - ANCCT \\ Lisboa, Portugal \\ asouza@cienciaviva.pt, aalves@cienciaviva.pt
}

\author{
Sofia Rodrigues \\ sofiarod1973@gmail.com \\ Lisboa, Portugal
}

\author{
Cristina Azevedo Gomes \\ Escola Superior de Educação de Viseu, Instituto Politécnico \\ de Viseu (ESEV, IPV) \\ Viseu, Portugal mcagomes@esev.ipv.pt
}

\author{
Maria João Silva \\ Escola Superior de Educação de Lisboa, Instituto \\ Politécnico de Lisboa (ESELx, IPL) \\ mjsilva@eselx.ipl.pt
}

\begin{abstract}
The teaching and learning experience, reported in this paper, aims at empowering schoolchildren in the promotion of environmental health in schools, emphasizing the role of Information and Communication Technologies in such promotion. Sound sensors (integrated in tablets) together with a free app were used by children to improve their awareness in what concerns noise, and its consequences. A set of strategies were designed and implemented to support children in making sense of the use of sound sensors in the specific context of a science museum school, with their own teachers, and where each class stays only for a week. Children's registers and answers to a satisfaction questionnaire contributed to validate the developed strategy. Primary school teachers' feedback made it possible to follow-up the experience. The dissemination of the experience to other primary schools is being planned in the context of a research project on Environmental Health (Eco-sensors4Health).
\end{abstract} health

Keywords- sound; sensors; schoolchildren; environmental

\section{INTRODUCTION}

The research presented in this paper is part of the Ecosensors4Health project, which aims at empowering primary schoolchildren in the promotion of environmental health in schools, emphasizing the role of Information and Communication Technologies (ICT) in this promotion, while developing children's health literacy. This way, Ecosensors4Health is a health promotion project, centred on the empowerment (of children), considered as a process through which people gain greater control over decisions and actions affecting their health [1].

The World Health Organization defines Health Literacy as "the cognitive and social skills which determine the motivation and ability of individuals to gain access to, understand and use information in ways which promote and maintain good health"
[1]. Since school years are determinants of health through life, schools are considered key settings for health literacy development [2].

The Portuguese Plan for School Health acknowledges noise as a schools' environmental risk [3]. Environmental noise affects children's health, causing annoyance responses, stress and lower wellbeing, as well as negative cognitive effects, such as less reading comprehension, long-term memory and performance on tests [4]. Furthermore, noise can cause fatigue and interruptions in the communication between teachers and children, as well as a reduction of morale and motivation in teachers [4].

ICT have been recognized as important in developing health literacy [5]. Mobile devices are nowadays widely used as tools for encouraging physical activity and healthy diets, for symptom monitoring in asthma and heart disease, for sending patients reminders about upcoming appointments, and for a range of other health problems [6]. This research uses mobile devices to enable children to sense sound level in indoor and outdoor school environment, in order to understand and improve, through decision-making, the school's environmental health.

Following this introduction, the next section presents fundamental related work. Subsequently, the methods and techniques are specified in the Methodology section. Results are, then, presented and analysed. Conclusions and future work are outlined before the References section.

\section{RELATED WORK}

Since the beginning of the 21 st century, and especially after the release of easy to use collaborative map tools, diverse educational projects built/exploited mobile devices, in 
georeferenced environmental sense making activities. Examples of such projects are: Ambient Wood [7]; MobGeoSens in Schools [8], Urban Tapestries and Social Tapestries [9]. Tools such as mobile phones, GPS sensors, as well as other environmental sensors were used in a participatory way in all the above mentioned projects to monitor environmental and health parameters.

The projects TEEMSS2 [10] and POLLEN [http://www.cienciaviva.pt/projectos/pollen/] used the EUROSENSOR [11] and produced inquiry-based instructional science units for elementary schools, to support teachers in scaffolding children in the use sensors (including sound sensors) to explore environmental dimensions and multiple representation of such dimensions.

A personal mobile toolkit (nQuire) was developed in another project [12] to support teachers and children in science inquiry activities, using sensors in school but also outdoors and at home to address broad areas of the school science curriculum, such as personal health.

In the SchoolSenses@Internet project, children used human senses and GPS equipped mobile phones to create multisensory georeferenced information, this way learning new dimensions of the schoolyard environment, creating multiple views of environmental quality and having a voice in the environmental assessment of their schoolyards [13].

The USense2Learn project added environmental sensors to the mobile creation of georeferenced multisensory information, making it possible to bring quantitative and qualitative visions of the outside world into the classroom and to share it with other classrooms, using Google Earth [14].

In the study, presented in this paper, children were invited to use free software and tablets to explore sound and to sense sound level, in a science museum school, to improve their environmental health awareness.

\section{METHODOLOGY}

\section{A. Context and participants}

Ciência Viva School (CVS) is the first museum-school project in Portugal, the first primary school operated by a scientific institution in a science centre, where scientists and educators use practical work and cutting edge technology to reshape science education and promote scientific culture. It is an on-going project from Ciência Viva, The Portuguese National Agency for Scientific Culture, hosted by the largest science centre in the country - the Pavilion of Knowledge, in Lisbon.

CVS is a community project addressing the needs of teachers, students and their families, with a new model of schooling. Classrooms and other school facilities were built within the science centre to host intensive week-long programmes of experiential science learning, with both handson and inquiry-based learning approaches.

CVS is an intense experiential learning approach, focused on hands-on and inquiry-based learning with a clear technological engagement, which promotes a weekly schedule of activities in different settings: classroom, laboratory, "kitchen is a lab", exhibitions and the student-scientist dialogue, where students interact face-to-face with some of the best scientists in Portugal, from a wide variety of science research domains.

The participants in this teaching and learning experience were three CVS teachers/researchers, another researcher, and 904 students from 42 classes of the 3rd and 4th grades, from 38 Lisbon public primary schools. Most of the children were aged 8 to 10 years old, with 461 being boys and 443 girls, as shown in Table 1.

TABLE I. PARTICIPANTS

\begin{tabular}{|c|c|c|c|c|c|c|c|c|c|c|}
\hline \multirow[b]{2}{*}{ Primary schools } & \multirow[b]{2}{*}{ Year of scholarity } & \multirow[b]{2}{*}{ Classes } & \multirow[b]{2}{*}{ Students } & \multicolumn{2}{|c|}{ Sex } & \multicolumn{5}{|c|}{ Age } \\
\hline & & & & M & $\mathbf{F}$ & 7 & 8 & 9 & 10 & +10 \\
\hline \multirow{3}{*}{38} & 3rd year & 17 & 370 & 186 & 184 & 25 & 284 & 52 & 5 & 4 \\
\hline & 4th year & 25 & 534 & 275 & 259 & 0 & 10 & 387 & 92 & 45 \\
\hline & Total & 42 & 904 & 461 & 443 & 25 & 294 & 439 & 97 & 49 \\
\hline
\end{tabular}

\section{B. Data collection and recording}

In this study, in order to validate the teaching and learning experience the teachers/researchers used participant observation and the data collected and registered by children.

In the teaching and learning experience, sound level was measured by groups from 4 to 5 children, using the sound sensors integrated in 6 tablets (iPads) and the free SPARKvue app. With each class, sound level data was collected in two different moments, one inside the classroom and another one outdoors, in the garden, located on the lateral zone of the Pavilhão do Conhecimento.

In a first moment, students were asked to measure and record on a record sheet (Fig. 1) the values of sound level when in silence, while clapping and in group work. In the record sheet, a free field was purposely endorsed to another measurement situation, decided by children, for instance when whispering, singing, or yelling. All the data acquired with the sensor was registered in the record sheet, together with sentences about what children sensed and felt in each situation.

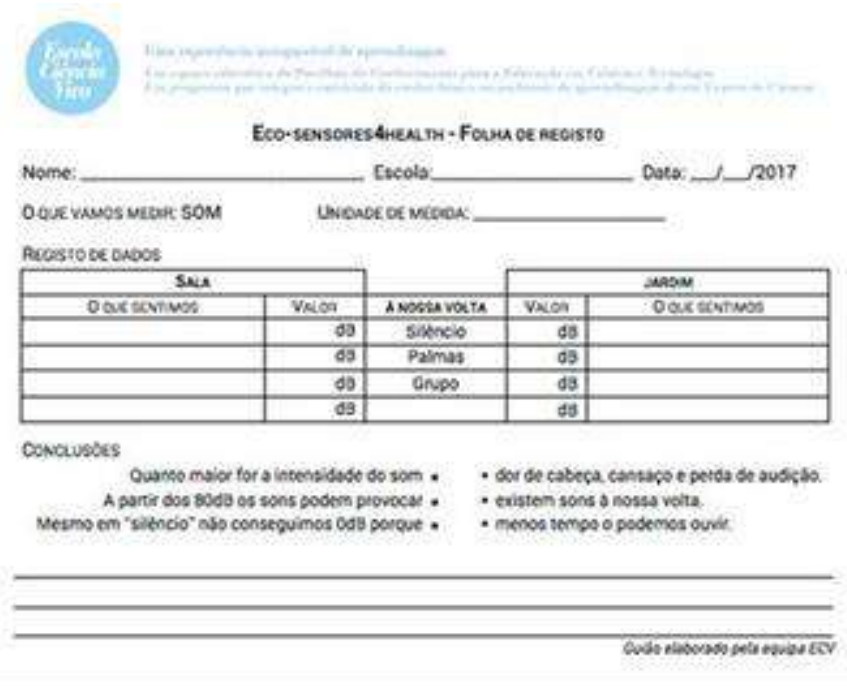

Fig. 1. - Record sheet to be filled by children 
Subsequently, the groups of children collected and registered sound level data, in similar situations, but outdoors.

To assess children's satisfaction regarding the developed activities, a questionnaire was applied to each child, in the last day of activities. The questionnaire used an attitude scale (Likert scale), with four levels of satisfaction (Liked a lot, Liked, Liked a little, Didn't like).

\section{The method of the teaching and learning experience}

This teaching and learning experience took place along three sessions, lasting about two hours, structured into different stages (Table II), and designed iteratively, following participant students' answers and their teachers' feedback.

\section{TABLE II. STRUCTURE OF THE EXPERIENCE (SESSIONS AND STAGES}

\begin{tabular}{|l|l|l|}
\hline 1st session & \multicolumn{1}{|c|}{ 2nd session } & 3rd session \\
\hline What is sound? & $\begin{array}{l}\text { Measuring } \\
\text { recording }\end{array}$ & Data and \\
\cline { 3 - 3 } $\begin{array}{l}\text { What is needed to } \\
\text { have sound? }\end{array}$ & Data interpretation \\
\hline $\begin{array}{l}\text { What sounds do we } \\
\text { produce? Measuring } \\
\text { and recording. }\end{array}$ & Sound propagation & Conclusions \\
\cline { 3 - 3 } & & Concluding Video \\
\hline
\end{tabular}

The development of this experience faced diverse challenges. The first one was how to develop this learning process through inquiry. The second challenge was how to approach the concept of sound (first session). In order to overcome this challenge, using concreteness fading (the successively decreasing of the concreteness of the representations, to attain an abstract representation that is still connected to the situation represented) [15]. The sound concept was first approached, making use of different manipulable materials. These materials were also used to develop the conclusions, during the third session.

The experience developing process was also paved with successes, such as the motivational potential of some tasks, such as using the sensors integrated in the tablets together with the SPARKvue app to acquire and read data.

In the first stage of the first session, children were asked about the different factors that affect comfort inside the school. Noise (also referred as "sound", "racket", "screams") has been one of the factors mentioned as producing uncomfortable conditions. The second stage was developed according to the ideas collected in the first one and was supported by a PowerPoint presentation. It aimed at giving children the opportunity to understand, in a concrete and sensory way, what sound is, how it propagates, or not, and what is needed to have sound. This was achieved through the use and exploration of diverse manipulable materials, such as speaking with one hand on the throat, strumming the strings of a guitar, and striking a wire clothes hanger with a pencil. In stage three, an inquiry project was proposed to children, aiming at studying the sounds produce by their own in two different contexts: inside the classroom and in the playground. In order to carry this out, children were introduced to: the record sheet (Fig. 1), the sound sensors, integrated in the iPads, the SPARKvue app, and to the decibel measurement unit. Data collection inside the classroom was then initiated, and the results were registered by children in the record sheet.

The second session took place in the playground and was divided into two stages. During the first stage, the tablets were distributed, one per work group (4 to 5 children), and each group was responsible for measuring and registering sounds produced by themselves in different situations. Children were asked to be especially careful in positioning the sensor towards the sound source. The second stage consisted in studying the propagation of sound, positioning four children, each one with a tablet, at specific linear distances $(1 \mathrm{~m} ; 8 \mathrm{~m} ; 15 \mathrm{~m} ; 22 \mathrm{~m})$ from the sound source (the other children of the class that were producing sounds). The data acquired by each of those four children showed that sound level diminishes with distance.

The third session was developed inside the classroom, and comprised four stages. In the first stage, children with teacher mediation, registered the statistical average, as well as the maximum and the minimum of the values gathered by each group. In the second stage, the acquired data were compared by children to a sound scale (Fig. 2), and all values that were potentially hazardous to hearing, were highlighted. The sound scale shows the safe (green to yellow) and dangerous (yellow to orange) sound levels, as well as the sound levels produced by everyday sound sources, such as people whispering, people talking, street traffic, rock concert, and airplane take off. It also shows the environmental sound level that calls for the use of hear protection.

The potential damage of high sound levels was illustrated using a taut transparent film and a slightly loose transparent film. The stretched film represents the healthy eardrum and the other represents the tired/damaged eardrum. Children observed the behaviour of sugar crystals on the two films, when sound vibrations were produced. The sound source was created hitting a plastic bottle with a wooden stick. On the stretched film the sugar vibrates and on the other the vibration of the sugar is much smaller or almost non-existent. This way, children could understand what could happen to human eardrum when damaged by noise (high levels and long exposures).

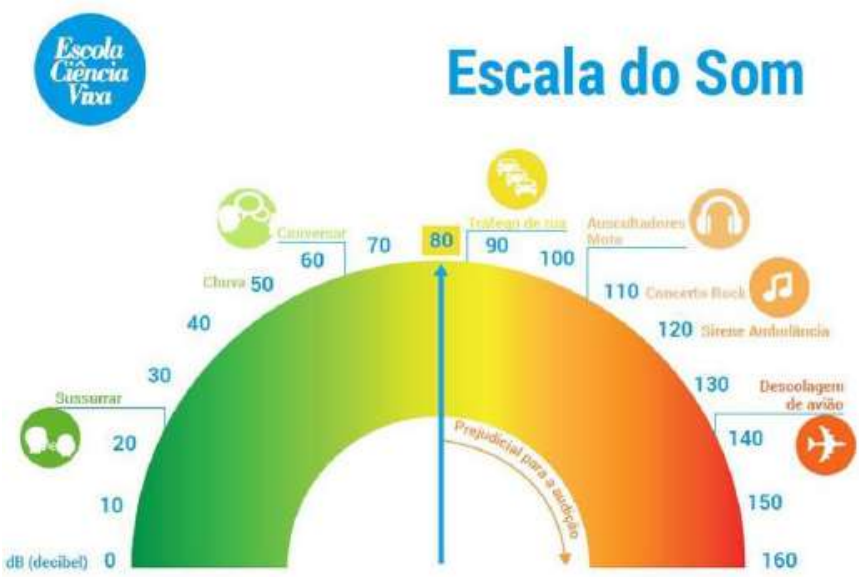


Fig. 2 - Sound scale

Conclusions were drawn from these assessments in the stage three. The experience closed by showing the "Irreparable damage" video (https://www.napofilm.net/pt/napos-films/napostop-noise/irreparable), aiming at conveying the message that our hearing cannot be replaced, and how we should take care of it.

\section{RESULTS: PRESENTATION AND ANALYSIS}

\section{A. The teaching and learning experience}

In all the sessions, children engaged enthusiastically in using the sound sensors, integrated in the tablets. They were fast in understanding how to use the sensors to acquire and register sound level data in diverse locations. While efficiently acquiring data with the tablets and registering in the record sheet (see Fig. 3), children produced the diverse required sounds (see Fig. 4), and sometimes they didn't control the enthusiasm. In those situations, some conflicts and small accidents with the tablets were created. On the other hand, occasionally, it was necessary to repeat a group proceeding, since sometimes children missed focus and meticulousness, when trying to produce higher sound levels (Figure 4).

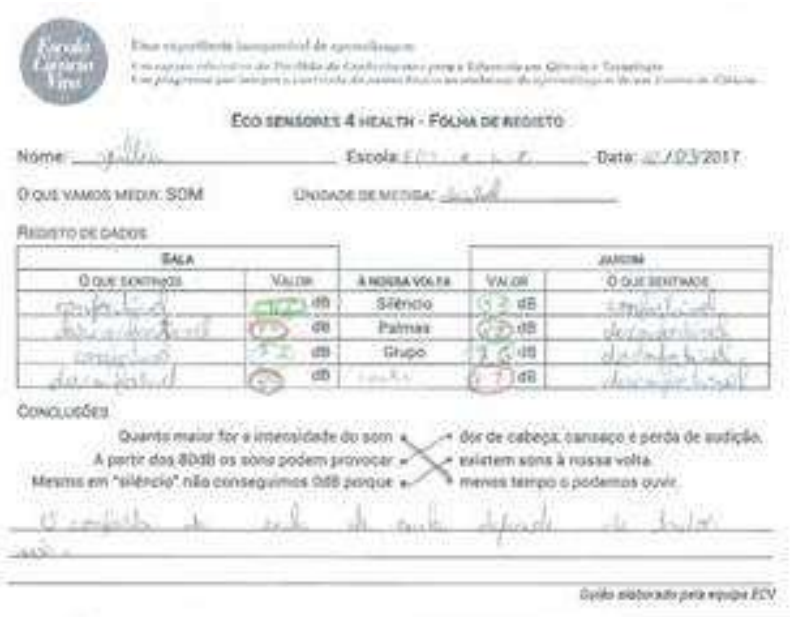

Figure 3 - Filled record sheet

The use of technology was a motivating factor, since all children reacted positively to the proposed tasks. Technology was not an obstacle and all the groups were able to read the instantaneous values, as well as the minimum and maximum values, using the SPARKvue app in the iPAD (Fig.5).

The register sheet was important as a support to: i) focus on the conditions to acquire sound level data; ii) signify the acquired data; iii) reify the sensations of dis/confort, while exposed to diverse sound levels; iv) make explicit conclusions, such as the non-existence of silence, the consequences of noise and security rules.

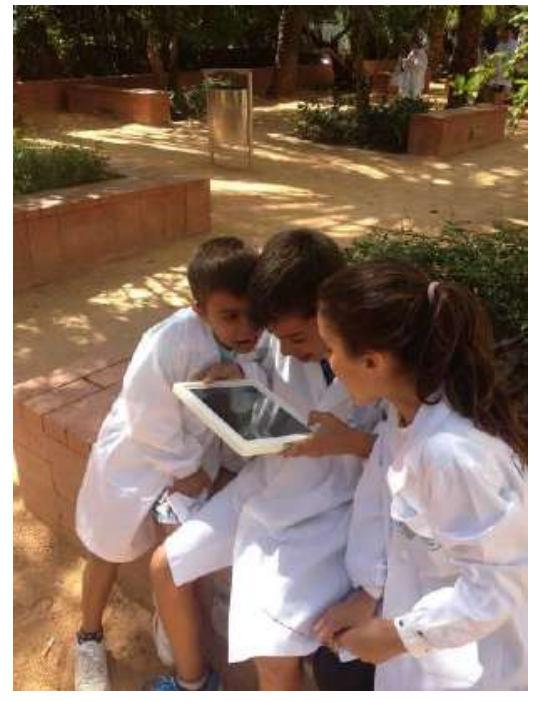

Fig. 4 - Children using the sound sensor, integrated in the tablet, together with the SPARKVUE app, while producing sounds.

Children's registers were summarized in Table III that shows the maximum and minimum values in the diverse environmental conditions. Children could signify the obtained values, namely by verifying that: i) the minimum values were obtained, when they made silence; ii) the maximum values were obtained, when they clapped their hands or sang; iii) sound levels during workgroup were closer to the usual value in the classroom and were close to the safe limits; iv) in the presence of the same sound sources, sound levels were higher in the classroom than in the garden, due to sound propagation and sound reflection.

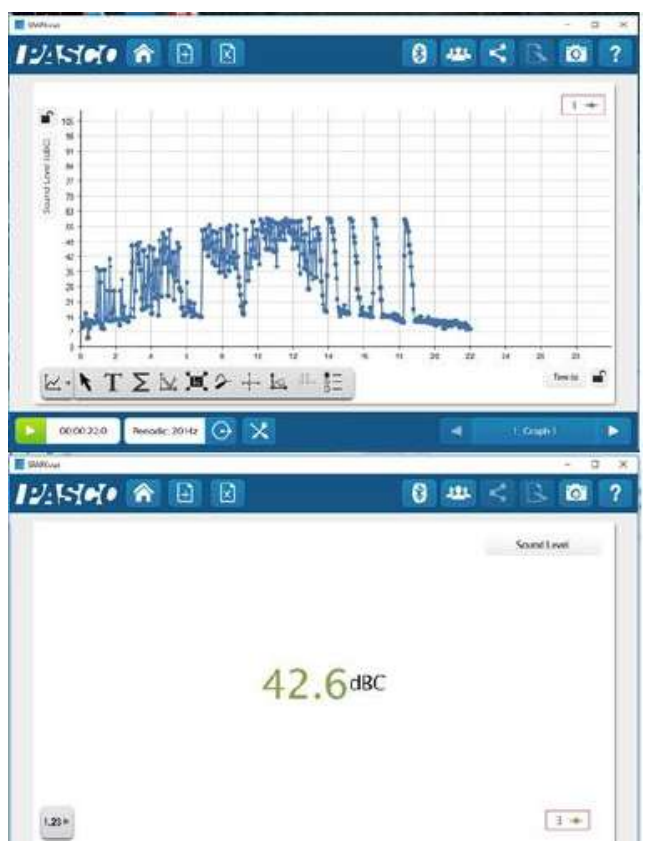

Fig. 5 - Interface of the SPARKvue app, showing a graph and a instantaneous value. 
TABLE III. SOUND LEVEL VALUES INTERVALS IN DIVERSE LOCATIONS

\begin{tabular}{|c|c|c|}
\hline Classroom & & Garden \\
\hline Value (dB) & Environment & Value (dB) \\
\hline $36-42$ & Silence & $50-61$ \\
\hline $82-88$ & Clapping hands & $70-88$ \\
\hline $72-80$ & Workgroup & $70-79$ \\
\hline $82-91$ & Singing & $80-82$ \\
\hline
\end{tabular}

At the end of the teaching and learning experience, which lasted for six months, the answers of the participant students to the questionnaire with the attitude Likert scale were processed. Those answers were given by children at the end of each week of class activities in the ECV. From the 904 participant students, $792(87,61 \%)$ answered to the satisfaction questionnaire, because not always all the children of a class attended the teaching and learning experience or were present at the time of the assessment.

From the 792 children that answered to the questionnaire and assessed the activity, 52\% (412) reported that they "Liked a lot", 37\% (293) said they "Liked", 69 said they "Liked a little", and only $2,3 \%$ (18) mentioned that they "Didn't like" (Table IV). This way, the assessment was clearly positive.

TABLE IV. STUDENTS' SATISFACTION AS REGARDS THE ECO-SENSORS4HEALTH ACTIVITY

\begin{tabular}{|c|c|c|c|c|c|c|}
\hline & $\begin{array}{c}\text { Liked a } \\
\text { lot }\end{array}$ & Liked & $\begin{array}{c}\text { Liked a } \\
\text { little }\end{array}$ & $\begin{array}{c}\text { Didn't } \\
\text { like }\end{array}$ & $\begin{array}{c}\text { Students } \\
\text { that } \\
\text { assessed } \\
\text { the } \\
\text { activity }\end{array}$ & $\begin{array}{c}\text { Participant } \\
\text { students }\end{array}$ \\
\hline $\begin{array}{c}\text { Number of } \\
\text { students }\end{array}$ & 412 & 293 & 69 & 18 & 792 & 904 \\
\hline$\%$ & $52 \%$ & $37 \%$ & $8,7 \%$ & $2,3 \%$ & $87,6 \%$ & $100 \%$ \\
\hline
\end{tabular}

\section{B. Follow-up}

In the day after the use of sound sensors, many children have been telling teachers/researchers that they have downloaded the SPARKvue app to the tablet or smartphone and that they have already used it to measure sound level at home with the family.

Some primary school teachers of the participant students told the teachers/researchers that they have continued the activity in their schools. In a fourth grade class, the teacher installed the SPARKvue app in a tablet, and used it to constantly monitor classroom sound level. The teacher defined weekly goals and supported children in calculating average and mode and in identifying the maximum and minimum to reflect on. Teachers of other schools also decided to follow up the work, replicating, with other classes of the school, the activities carried out. Other teachers of another school shared the experience and the discoveries made in ECV with the school community, on the school open day. In that day, some parents downloaded the app to their smartphone.
In the oral assessment of the project activity, primary school teachers have been giving positive feedback to the developed activity, not only because "Sound and Noise" is an important topic, but also because this activity is a contribution to approach a significant problem in schools: the noise produced by children in the school, in general, and in specific spaces such as the school canteens, in particular.

When the teachers/researchers asked primary school teachers about the pertinence of developing activities on other environmental health topics, primary school teachers answer that it could be interesting, but emphasize that the topic "Sound and Noise" is very useful and that the developed activity gives support to work on one of the current environmental health school problems, this way contributing to individual and environmental health.

\section{CONCLUSION AND FUTURE WORK}

The research, presented in this paper, developed a teaching and learning experience that integrates a set of strategies to support children in making sense of the use of sound sensors in the specific context of a science museum school, with their own teachers, and where each class stays only for a week. Children's registers and answers to a satisfaction questionnaire contributed to validate the developed strategy. Teachers' feedback made it possible to follow-up the experience.

In this teaching and learning experience, which was implemented with each class in three days of a week in a total of two hours, children used everyday objects to a first approach of the concept of sound, and they used sensors to explore sound level in the CVS indoor and outdoor environment, this way following a concreteness fading strategy.

Children's registers and the conclusions of each class made it clear that children became aware of: the risks of long exposures to high sound levels; the fact that they weren't able to produce total silence; the fact that the same sounds result in higher sound levels in the classroom than in the garden; that sound level decreases with the distance to the sound source.

Children learned in a enthusiastically way how to: i) sense the sound in concrete ways, using their sensors and manipulable materials; ii) use the sound sensors, producing recordings; iii) interpret and signify the produced recordings; iv) control variables in an embodied way, as was the case of the study of sound propagation; v) produce conclusions. This way, it was possible to achieve the goal of implementing this learning process through inquiry.

The assessment, using the satisfaction questionnaire that was answered by participant children, was very positive, since only $2,3 \%$ of the participant children, answering that they didn't like. Furthermore, the feedback of the primary schools was also very positive, emphasising the pertinence of the topic and the strategy. Some of those teachers continued the experience in their own schools.

The presented results validated the teaching and learning experience, supporting the project of using it in the future and in other schools. The dissemination of the experience to other 
primary school is being planned in the context of a research project on Environmental Health (Eco-sensors4Health).

In future work, the teaching and learning experience will be enhanced with the use of sound barriers to support children in envisioning solutions to noise problems.

\section{ACKNOWLEDGEMENTS}

We acknowledge Pedro Brogueira, Professor at Instituto Superior Técnico, for his important contribution to practical activities developed with children.

\section{REFERENCES}

[1] World Health Organization (WHO), Health Promotion Glossary, WHO/HPR/HEP/98.1, 1998.

[2] L. Kilgour , N. Matthews , P. Christian and J. Shire, "Health literacy in schools: Prioritising health and well-being issues through the curriculum", Sport, Education and Society, 2013. DOI: $10.1080 / 13573322.2013 .769948$

[3] S.Stansfeld, and C. Clark, "Health Effects of Noise Exposure in Children", Curr. Environ. Health Rep., vol. 2, pp.171-178, 2015. DOI: $10.1007 / \mathrm{s} 40572-015-0044-1$

[4] von Amann, G. (Org.), Programa de Saúde Escolar 2015. DGS, 2015.

[5] United Nations Economic and Social Council (ECOSOC), "Health Literacy and the Millennium Development Goals: United Nations Economic and Social Council (ECOSOC) Regional Meeting Background Paper (Abstracted)", Journal of Health Communication, vol. 15:S2, 211-223, 2010. DOI: 10.1080/10810730.2010.499996.

[6] P. Klasnja and W. Pratt, "Healthcare in the pocket: Mapping the space of mobile-phone health interventions", Journal of Biomedical Informatics, n. 45, pp. 184-198, 2012.

[7] Y. Rogers, S. Price, C. Randell, D. Stanton-Fraser, M. Weal, and G. Fitzpatrick, "Ubi-learning: Integrating Outdoor and Indoor Learning Experiences", Communications of the ACM , n. 48, vol. 1, 55-59, 2005.
[8] E. Kanjo, S. Benford, M. Paxton, A. Chamberlain, D. S. Fraser, D. Woodgate, D. Crellin, and A. Woolard, "MobGeoSen: Facilitating Personal Geosensor Data Collection and Visualization Using Mobile Phones", Personal and Ubiquitous Computing, n. 12, vol. 8, SpringerVerlag, 2008.

[9] A. Angus, G. Lane, K. Martin, D.Papadogkonas, G. Papamarkos, G. Roussos, S. Thelwall, Z. Sujon, and N. West, Urban Tapestries: Exploring Public Authoring in the City, SCSIS Technical Report. Birkbeck: University of London, 2007.

[10] A. Zucker, R. Tinker, C. Staudt, A. Mansfield, and S.Metcalf, "Increasing Science Learning in Grades 3-8 Using Computers and Probes: Findings from the TEEMSS II Project", in Proceedings of the NARST 2007 Annual Meeting, 2007.

[11] E. van den Berg, F. Schweickert, and R. van den Berg, (2010). Science, Sensors and Graphs in Primary schools, in Proceedings of the GIREP Conference 2010.

[12] M. Sharples, E. Scanlon, S. Ainsworth, S. Anastopoulou, T. Collins, J. Crook, A. Charles, L. Kerawalla, K. Littleton, P. Mulholland, and C. O'Malley (2015). Personal inquiry: orchestrating science investigations within and beyond the classroom. Journal of the Learning Sciences, 24(2) pp. 308-341.

[13] M. J. Silva, C. A. Gomes, B. Pestana, J. C. Lopes, M. J. Marcelino, , C. Gouveia, and A. Fonseca, "Adding Space and Senses to Mobile World Exploration", in Mobile Technology for Children, A. Druin (ed.), pp. 147-170. Boston: Morgan Kaufmann, 2009.

[14] M. J. Silva, J. C. Lopes, P. M. Silva, and M. J. Marcelino, "Sensing the Schoolyard: Using Senses and Sensors to Assess Georeferenced Environmental Dimensions", in Proceedings of ACM 1st International Conference and Exhibition on Computing for Geospatial Research \& Application, ACM, 2010.

[15] R. Goldstone, and J. Son, "The Transfer of Scientific Principles Using Concrete and Idealized Simulations", Journal of the Learning Sciences, n. 14, vol. 1, 69-110, 2005. 